\title{
Predictive Factors for Positive HIV Test Results in a Hospital Setting
}

\author{
Sulmaz Ghahramani (iD ${ }^{1}$, Hassan Joulaei $\mathbb{D}^{2}{ }^{2}$, Amir Human Hoveidaei $\mathbb{D}^{3,4}{ }^{3}$, Mohammadreza Rajabi ${ }^{3}$ \\ and Kamran Bagheri Lankarani ${ }^{1, *}$ \\ ${ }^{1}$ Health Policy Research Center, Institute of Health, Shiraz University of Medical Sciences, Shiraz Iran \\ ${ }^{2}$ Shiraz HIV|AIDS Research Center, Institute of Health, Shiraz University of Medical Sciences, Shiraz Iran \\ ${ }^{3}$ Student Research Committee, Shiraz University of Medical Sciences, Shiraz, Iran \\ ${ }^{4}$ Students' Scientific Research Center, Tehran University of Medical Sciences, Tehran, Iran \\ Corresponding author: Health Policy Research Center, Institute of Health, Shiraz University of Medical Sciences, Shiraz Iran. Email: kblankarani@yahoo.com \\ Received 2020 January 26; Revised 2021 July 13; Accepted 2021 August 15.
}

\begin{abstract}
Background: Hospital admission for any reason provides the situation for voluntary HIV testing and consultation. Identifying the predictors of positivity may lead to a cost-effective method while enhancing professionalism.

Objectives: To find the predictors of HIV-positive test result in a general hospital in Shiraz compared to a control group.

Methods: In this case-control study, the records of all patients who received HIV testing upon their hospitalization in a general hospital in Shiraz, south of Iran, from January 2017 to the end of December 2017 were reviewed. For each HIV-positive case, at least one control from the same ward in the hospital with negative HIV test result was randomly selected. Based on the best-fitted model of logistic regression, the probability of positive HIV test results was estimated for each participant according to the risk factors, and a receiver operating characteristic (ROC) curve was drawn.

Results: Out of 7333 persons who accepted to be tested, 77 patients tested positive for HIV, of whom 55 (71.4\%) were male with the mean age of $41.5 \pm 9.5$ years. None of the HIV-positive patients were intravenous drug users, nor had they a history of imprisonment. The odds ratio (OR) was 21 for hepatitis-positive patients (hepatitis B and/or C) compared to negative ones, which was seven times higher in opium addicts than non-opium addicts. We developed a model using age, sex, opium addiction, and HBV and HCV status to predict the probability of being positive for HIV with an AUC of 0.853 (95\% confidence interval 0.797 to 0.909 ).

Conclusions: Hospital admission could be an appropriate momentum for providing voluntary counseling and testing. Infection with HBV and HCV are important risk factors for HIV infection, and additional testing should be offered, especially to these patients.
\end{abstract}

Keywords: Predictive, Hospital, Positive HIV Test

\section{Background}

HIV is mainly a blood-borne infection, which is transmissible through sexual contact. Researchers have introduced various HIV infection risk factors, including unsafe sex, men who have sex with men (MSM), polygamy, female sex workers (FSWs) and their clients, sexually transmitted diseases, substance use, whether injection drug use (IDU) or non-injection illicit drug use (NIDU), maternal HIV infection, being a refugee, and imprisonment (1-10). With the increased spread of HIV infection to the general population from high-risk individuals to other persons, there is a growing need for early detection, which can itself lead to the prevention of newly acquired cases. Early detection of new HIV cases is critical in regions with low education and severe health resource constraints.

Hospital admission could be the momentum for vol- untary counseling and testing (VCT) and finding new cases of HIV infection, and identifying previously undiagnosed cases of HIV infection (11-14). In 2004, approaches to the application of HIV counseling, testing, and referring were proposed by the US Centre for Disease Control and Prevention (CDC) (9). Nonetheless, in 2007, WHO/UNAIDS guidelines recommended HIV testing as a part of the standard medical care (15). This guideline clearly states that provider-initiated HIV testing and counseling in concentrated epidemic areas should not recommend HIV testing and counseling to ALL people referring to all health facilities. However, selected health facilities in concentrated epidemics should be treated differently, and populations most at risk for HIV infection transmission in these settings need to have access to counseling, testing, and refer$\operatorname{ral}(15)$.

Iran is now at a concentrated level for HIV infection, 
and although a national guideline for the management of HIV/AIDS patients currently exists, this guideline does not explicitly include a recommendation for in-hospital HIV counseling and testing $(7,16)$.

There is limited evidence on the true prevalence of HIV positive referrals (both known and new cases of HIV infection) to hospital settings of Iran. However, it is evident that the use of traditional risk factors as a guide for HIV testing in the hospital setting may not be feasible because of perceived stigma and discrimination, concerns about the confidentiality of results, poor attitude, cultural barriers, or limited available time of healthcare providers (8, 17-23). In this situation, seropositive HIV patients may be lost; thus, there should be other predictors in history and physical examinations and hospital presentation of referred patients, which could be asked in the routine history taking in hospitals.

\section{Objectives}

Hospitals should provide the situation for VCT. Besides, healthcare providers should decide whether to order HIV test for patients or not. In other words, specific clinical and demographic factors associated with HIV-positive status in hospitalized patients has not been incorporated into testing practice, which underlines the importance of developing a systematic approach to testing the admitted patients for HIV infection in Shiraz hospitals. As a result of this, the predictors of HIV-positive test results in a general hospital in Shiraz are investigated in this study.

\section{Methods}

\subsection{Study Setting}

In this case-control study, records of all admitted patients who requested HIV testing during 12 months in 2017 were assessed. The record number of patients with positive HIV test results was extracted through Hospital Information system (HIS) to use the anonymous clinical data for research purposes in a university-affiliated general hospital of most-at-risk HIV-positive patients in Shiraz. Shiraz is the capital of Fars province, which is the largest province in southeast of Iran.

Opt-out provider-initiated testing and counseling HIV test for almost all admitted patients was requested after obtaining written informed consent. All patients admitted for one day or more with a requested HIV test and complete patient records during the study period were included.
Outpatient cases were excluded (due to the lack of registered records). Records with incomplete demographic, clinical, and behavioral data were excluded.

\subsection{Data Collection}

Records of HIV-positive patients were evaluated, and relevant data were collected within a data collection form. This form included demographic data (i.e., age, sex, education, nationality, place of residency, job and, insurance status, and readmission), clinical data (i.e., new case or known case, living status on discharge, physical examination, presentation on admission, TB status, and CD4 number), and behavioral data (i.e., the route in which the HIV infection has been acquired). Due to the first presentation's diversity, the cases were divided into the two categories of probably infectious causes (e.g., cough, fever, lymphadenopathy, rash, and jaundice) and other non-infectious presentations (e.g., fatigue, weight loss, body pain). In the case of two or more concomitant presentations, infection was considered positive. For each HIV-positive case, at least one control from the same ward was randomly (using the random number generator software) selected from the list of negative HIV test results. More control subjects were selected compared to cases to increase the power of the study. The same data were collected for the control group. One hundred control subjects were selected. Excluding three incomplete records, 97 control subjects were finally assessed. The present study was approved by the Ethics Committee (ethical committee code: 95-01-62-12889) of Shiraz University of Medical Sciences, Shiraz, Iran.

\subsection{Statistical Analysis}

Data were analyzed using descriptive and analytical methods through SPSS version 18.0 (SPSS Inc., Chicago, IL, USA). We used the chi-square test to compare qualitative variables and independent samples t-test and ANOVA for continuous variables. Independent variables with a Pvalue $<0.2$ in the univariate analysis were entered into the logistic regression model using stepwise forward selection. These variables included sex, age, education, hepatitis, opium addiction, iv drug use, prison history, smoking, and alcohol consumption. Statistically significant predictors were selected, and odds ratios were derived for these predictors. Age was divided into eight categories (every ten years); the first category was under 20 and the last one over 80 years.

Based on the best-fitted model of logistic regression, the probability of positive HIV test results was estimated for each participant according to the risk factors, and the 
receiver operating characteristic (ROC) curve was drawn. The area under the ROC curve (AUC) to measure how well the predictors can distinguish positive HIV test results was estimated. Sensitivity, specificity, and risk scores (based on the best fitted logistic regression model) were assessed. The significance level was set at 0.05 .

\section{Results}

During the study period, 7333 HIV tests were requested by the physicians. Out of these, 77 were HIV positive (one percent), and 19 patients were diagnosed for the first time (2 out of each 1000 test).

Most HIV-positive patients were male $(55=71.4 \%$ ). The mean age of the HIV-positive patients was $41.5 \pm 9.5$ years. Other characteristics of the participants are presented in Table 1. None of the participants in the control group had tuberculosis, positive history of imprisonment, or IV drug abuse. The risk factor evaluations of the participants are shown in Table 2. Mean \pm SD (median) of CD4 in the HIV group was $205 \pm 215$ (139).

Logistic regression results (for HIV positive/negative test results) based on the stepwise forward method using best predictors (predictors that were important, including gender, hepatitis, opium addiction, and age) are described in Table 3.

According to the logistic regression, after controlling the risk factors (i.e., hepatitis, opium addiction, and age) OR for positive HIV test result was 2.980 for women compared with men. Also, controlling the risk factors of the model (i.e., gender, opium addiction, and age) demonstrated that OR for positive HIV test results was nearly 21 for hepatitis-positive patients (hepatitis B and/or C) compared to negative ones. By controlling hepatitis, gender, and age, this study found that positive HIV test results were almost seven times more in opium-addicted patients than nonopium-addicted ones. Each 10-year increase in age corresponded with a $40 \%$ decrease in the chance of positive HIV test result after controlling the risk factors of the model (i.e., hepatitis, opium addiction, and gender).

After performing the logistic regression on data and the estimation of the best-fitted model, the probability of positive HIV test results was estimated for each patient according to the risk factors, and the ROC curve was derived (Figure 1).

The AUC was 0.853 with $95 \%$ confidence interval ( 0.797 0.909 ) (Table 4), and the model was good $(\mathrm{P}<0.001)$ for the prediction of positive test results (as a screening test

\begin{tabular}{|c|c|c|c|}
\hline Characteristics & HIV Case & Control & P-Value \\
\hline Number & & 77 & 97 \\
\hline Known* & 58 & & \\
\hline $\mathrm{New}^{* *}$ & 19 & & \\
\hline Age mean $\pm S D$ & & $49.83 \pm 20.1$ & 0.001 \\
\hline Known & $40.8 \pm 9.6(39)$ & & \\
\hline New & $43 \pm 9(45)$ & & \\
\hline Sex & & & 0.81 \\
\hline Male & & $68(69.8)$ & \\
\hline Known & $42(72.4)$ & & \\
\hline New & $13(68.4)$ & & \\
\hline Female & & $29(30.2)$ & \\
\hline Known & $16(27.6)$ & & \\
\hline New & $6(31.6)$ & & \\
\hline Education & & & 0.026 \\
\hline Illiterate & $15(22.4)$ & $37(40.2)$ & \\
\hline Educated & $52(77.6)$ & $55(59.8)$ & \\
\hline Nationality & & & 0.08 \\
\hline Persian & $68(89.5)$ & $93(95.9)$ & \\
\hline Afghan & $8(10.5)$ & $3(3.1)$ & \\
\hline Living status on discharge & & & 0.06 \\
\hline Live & $56(72.7)$ & $82(84.5)$ & \\
\hline Death & $21(27.3)$ & $15(15.5)$ & \\
\hline Place of residency & & & 0.4 \\
\hline Urban & $65(86.7)$ & $79(81.4)$ & \\
\hline Rural & $10(13.3)$ & $18(18.6)$ & \\
\hline Insurance & & 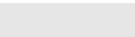 & 0.51 \\
\hline Yes & $66(85.7)$ & $84(86.6)$ & \\
\hline No & $11(14.3)$ & $13(13.4)$ & \\
\hline Job & & & 0.7 \\
\hline Unemployed & & $6(8)$ & \\
\hline Known & $4(7.5)$ & & \\
\hline New & $2(15.8)$ & & \\
\hline Employed & & $44(57)$ & \\
\hline Known & $33(62.3)$ & & \\
\hline New & $11(57.9)$ & & \\
\hline Retired & & $8(10)$ & \\
\hline Known & $2(3.8)$ & & \\
\hline New & 0 & & \\
\hline Housekeeper & & $19(25)$ & \\
\hline Known & $14(26.4)$ & & \\
\hline New & $5(26.3)$ & & \\
\hline
\end{tabular}

${ }^{\mathrm{a}}$ Values are expressed as No. (\%).

${ }^{\mathrm{b}}$, Known, known cases tested again for HIV; **, new, first time detection.

for the detection of HIV-positive patients) in more than $85 \%$ of cases.

The sensitivity and specificity of different risk scores are presented in Table 5. To better distinguish HIV-positive patients, a point on the ROC curve should be selected which has the highest sensitivity and reasonable speci- 


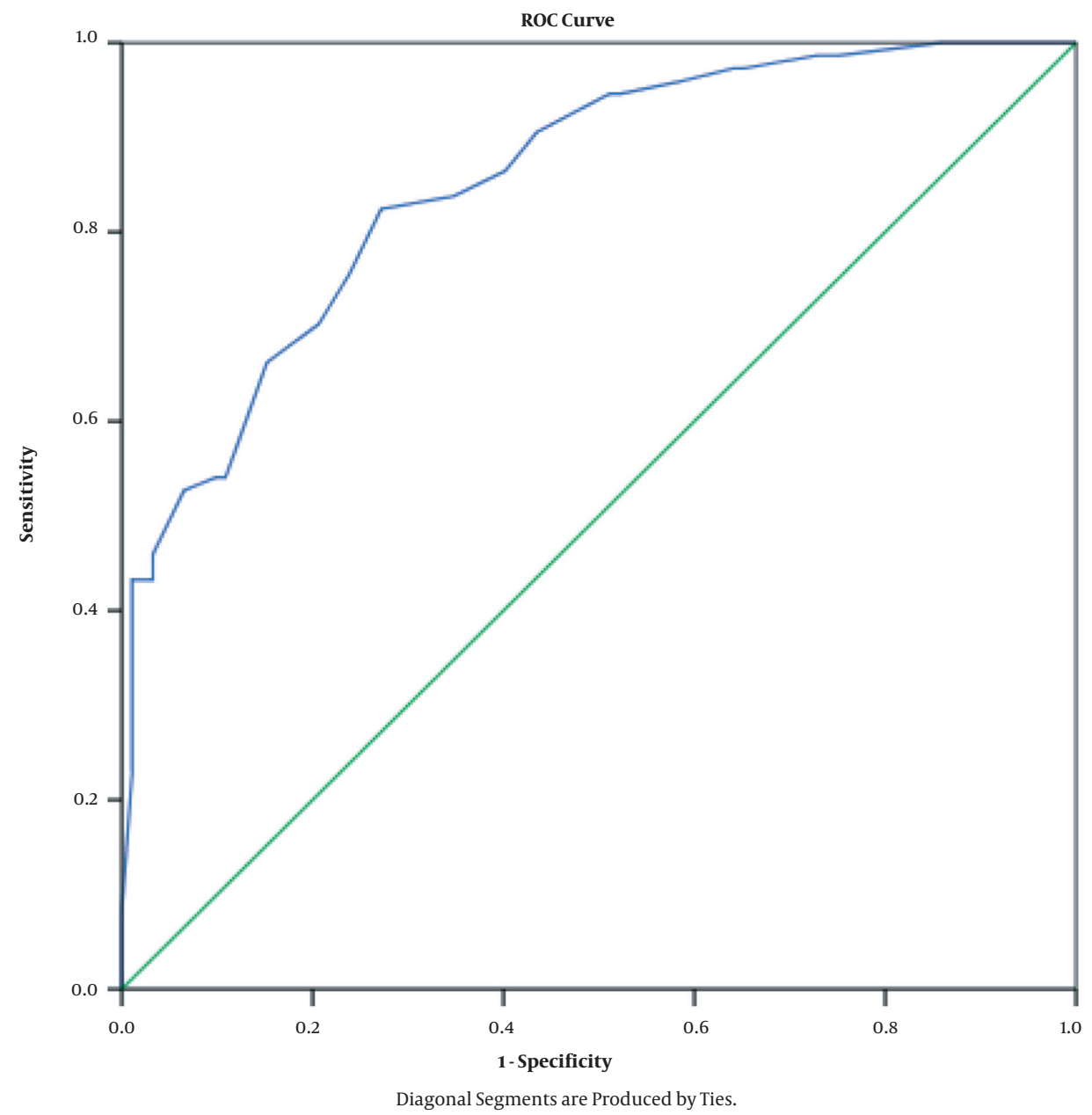

Figure 1. ROC curve for positive HIV test results

ficity. In Table 5, the cutoff point for risk score 0.2718 seems reasonable in which sensitivity is $90 \%$ with $60 \%$ specificity. The equation model for the calculation of the risk scores is: $\mathrm{P}(\mathrm{Y}=1)=1 /\left\{1+\exp ^{-(\mathrm{B} 1 \mathrm{X} 1+\mathrm{B} 2 \mathrm{X} 2+\mathrm{B} 3 \mathrm{X} 3+\mathrm{B} 4 \mathrm{X} 4)}\right\}$

$\mathrm{P}$ (for screening of HIV test) = $1 /\{1+$

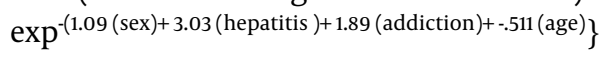

Risk score $=0.2718$

\section{Discussion}

This study showed that without the explicit recommendation criteria for counseling and testing HIV in a hospital setting, only $1 \%$ of those tested were diagnosed with HIV infection, and only $0.2 \%$ represented definitively newly recognized infections. This detection rate is lower than comparable observational and interventional studies and implies a waste of money and efficiency reduction $(6,13,24$ 26).

It is perceptible that around 25\% of HIV-positive cases were newly detected. This result shows that case finding in a hospital setting is extremely critical and can have numerous advantages. These benefits include the possibility to immediately start providing care, referrals for follow-up care after discharge, and its consideration as a setting for effective HIV infection diagnosis in patients' family members (12). However, the findings reveal that the rates of non-effective HIV testing is actually high, and more explicit recommendations for the effective detection of new infections is strongly recommended. The significance of early detection of HIV-positive cases is subjected to the first target of 90-90-90 approval: successfully diagnosing 90\% of 


\begin{tabular}{|c|c|c|c|}
\hline Risk Factors/Behavior & HIV Case & Control & P-Value \\
\hline Cigarette and/or Water pipe* & & & 0.018 \\
\hline Yes & $31(40.8)$ & $23(23.7)$ & \\
\hline No & $45(59.2)$ & $74(73.6)$ & \\
\hline Alcohol & & & 0.18 \\
\hline Yes & $2(2.7)$ & $8(8.2)$ & \\
\hline No & $73(97.3)$ & $89(91.8)$ & \\
\hline Opium addiction & & & $<0.001$ \\
\hline Yes & $48(64)$ & $22(22.7)$ & \\
\hline No & $27(36)$ & $75(77.3)$ & \\
\hline IV drug use** & & & 0.005 \\
\hline One time & $6(9)$ & 0 & \\
\hline More than one time & $1(1.5)$ & 0 & \\
\hline No & $60(89.6)$ & $97(100)$ & \\
\hline Imprisonment history & & & 0.015 \\
\hline Yes & $5(6.6)$ & 0 & \\
\hline No & $71(93.4)$ & $97(100)$ & \\
\hline Hepatitis coinfection & & & $<0.001$ \\
\hline Hepatitis B & $2(2.6)$ & $1(1)$ & \\
\hline Hepatitis C & $24(31.6)$ & 0 & \\
\hline Hepatitis B and C & $4(5.3)$ & 0 & \\
\hline No & $46(60.5)$ & $96(99)$ & \\
\hline Operation history & & & 0.86 \\
\hline Yes & $22(28.9)$ & $26(26.8)$ & \\
\hline No & $54(71.1)$ & $71(73.2)$ & \\
\hline Transfusion history & & & 0.30 \\
\hline Yes & $13(17.3)$ & $13(13.4)$ & \\
\hline No & $62(82.7)$ & $84(86.6)$ & \\
\hline Tuberculosis $^{* * *}$ & & & 0.001 \\
\hline Yes & $8(10)$ & 0 & \\
\hline No & $69(90)$ & $97(100)$ & \\
\hline \multicolumn{4}{|l|}{ Route of transmission } \\
\hline Sexual & $18(23)$ & & \\
\hline IV drug & $39(51)$ & & \\
\hline Other/not specified & $6(8)$ & & \\
\hline No data available & $14(18)$ & & \\
\hline
\end{tabular}

all HIV-positive people (27). The presence and implementation of explicit recommendations for emergency department (ED) and admitted patients, and consequently, offering routine HIV infection counseling, testing, and referral have improved the detection of new cases $(13,26)$. However, even with the presence of these recommendation, low rates of HIV testing in ED and inpatient settings is still a problem which requires further consideration (13).

This recommendation could be for patients presented with a risk score higher than 0.2718 in our setting. According to the proposed equation, risk score could be cal- culated based on gender, hepatitis B and/or C infection, opium addiction, and age as independent variables.

As stated beforehand, besides tuberculosis, positive history of prison and IV drug abuse are the conventional risk factors for HIV positive test results; in this hospital setting, female gender, hepatitis B and/or C patient, opium addiction, and younger age significantly predicted positive HIV test results. It is essential not to miss opportunities for detecting new HIV-positive test results in hospital settings, which could be momentum for VCT. The presented model for calculating the risk score for HIV test recommendation in this study could be an attempt toward diagnosing individuals at an earlier stage of HIV infection. However, there is not adequate national evidence for missed opportunities for the detection of new cases in hospital settings, but in France, it has been shown that missed opportunity for the detection of new HIV cases in healthcare facilities is still unacceptably high (28).

This study highlights positive HBV and/or HCV test results as an essential predictive factor for HIV positive test results (29-31). This picture is due to similar routes of transmission of HBV, HCV, and HIV infection. The detection of these co-infected patients in a hospital setting may help physicians with appropriated diagnosis and monitoring of chronic viral hepatitis as well as adequately confronting chronic viral hepatitis in HIV-positive patients $(30,31)$.

Logistic regression highlighted the female gender as a predictive factor in the proposed model of risk assessment. Although the prevalence of HIV infection in men is far more than in women in Iran (32), the greater susceptibility of women to HIV infection has been reported, which highlights the implications for culturally accepted interventions targeted to preventive strategies (33-35).

However, IDUs is known to be a significant risk factor for HIV infection, but it is also known that NIDUs are at higher risk for HIV infection transmission (4). The present investigation showed that opium addiction could be a predictive factor for positive HIV test results. The situation, however, needs to be deliberated case by case. As in a study in Brazil, transactional sex and in Tehran, the rapid transition of inhaled opium to injected opiates were highlighted as the essential risks for HIV infection transmission in NIDU individuals $(4,34)$.

It is noteworthy that the nature of this study was limited to the evaluation of causal linkage of the studied factors, and prospectively designed studies are recommended. Also, it is essential to mention that due to zero TB patients in the control group, this variable could not be assessed in the logistic regression model; however, accord- 


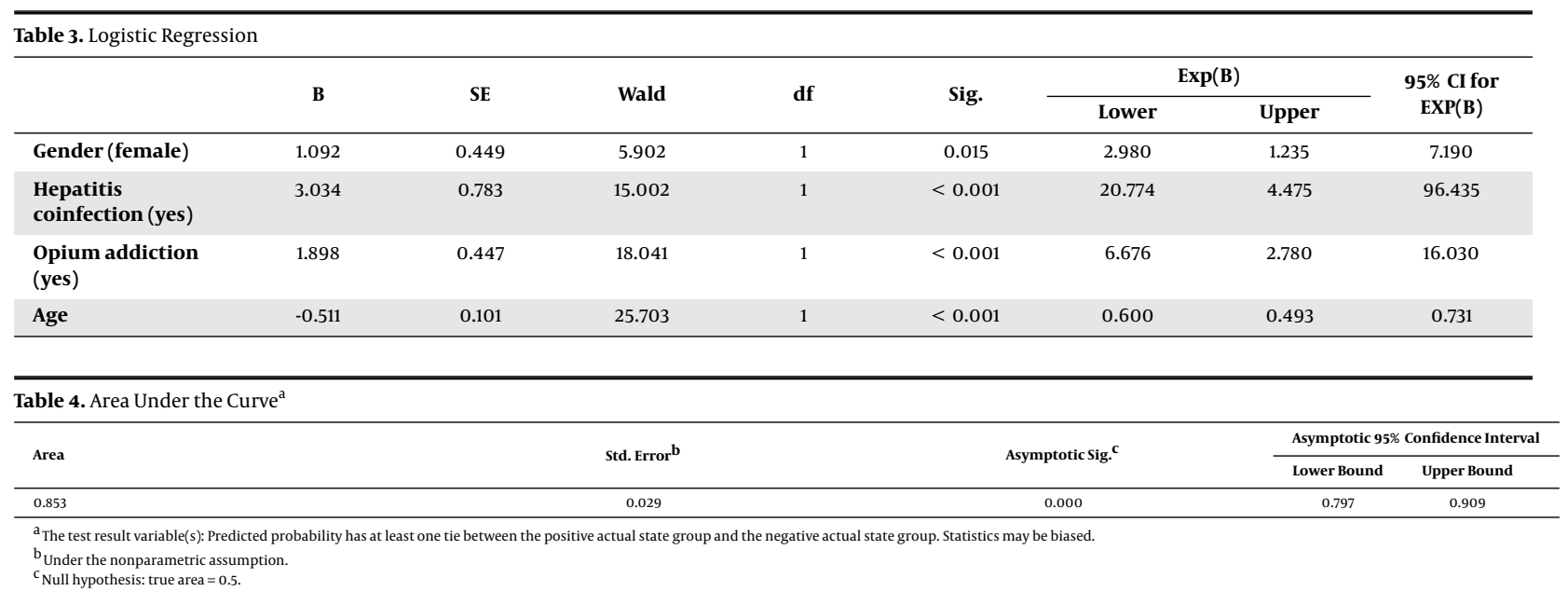

\begin{tabular}{ccc}
\hline Table 5. Coordinates of the Curve $^{\mathrm{a}}$ & & \\
\hline Positive if Greater Than or Equal to $^{\mathbf{b}}$ & Sensitivity & 1-Specificity \\
\hline 0.0000000 & 1.000 & 1.000 \\
\hline 0.0359638 & 1.000 & 0.924 \\
\hline 0.0584433 & 1.000 & 0.859 \\
\hline 0.0935411 & 0.986 & 0.750 \\
\hline 0.1185344 & 0.986 & 0.728 \\
\hline 0.1399653 & 0.973 & 0.652 \\
\hline 0.1677270 & 0.973 & 0.641 \\
\hline 0.1830364 & 0.959 & 0.587 \\
\hline 0.2130532 & 0.946 & 0.522 \\
\hline 0.2512982 & 0.946 & 0.511 \\
\hline 0.2718083 & 0.905 & 0.435 \\
\hline 0.3104118 & 0.865 & 0.402 \\
\hline 0.3585413 & 0.838 & 0.348 \\
\hline 0.3834209 & 0.824 & 0.272 \\
\hline 0.4279503 & 0.757 & 0.239 \\
\hline 0.4908962 & 0.703 & 0.207 \\
\hline 0.5541773 & 0.662 & 0.152 \\
\hline 0.5991746 & 0.541 & 0.109 \\
\hline 0.6245113 & 0.541 & 0.098 \\
0.6738154 & 0.527 & 0.065 \\
\hline 0.7134988 & 0.459 & 0.033 \\
\hline 0.7319197 & 0.432 & 0.033 \\
\hline 0.7716860 & 0.432 & 0.022 \\
\hline 0.8057889 & 0.432 & 0.011 \\
\hline 0.8146013 & 0.419 & 0.011 \\
\hline 0.8477019 & 0.378 & 0.011 \\
\hline 0.8833969 & 0.365 & 0.011 \\
\hline 0.9022581 & 0.338 & 0.011 \\
\hline 0.9228554 & 0.324 & 0.011 \\
\hline 0.9389075 & 0.311 & 0.011 \\
\hline 0.9575346 & 0.230 & 0.011 \\
\hline 0.9740474 & 0.000 \\
\hline 1.0000000 & & 0.000 \\
\hline
\end{tabular}

${ }^{\mathrm{a}}$ The test result variable(s): Predicted probability has at least one tie between the positive actual state group and the negative actual state group. ${ }^{\mathrm{b}}$ The smallest cutoff value is the minimum observed test value minus 1 , and the largest cutoff value is the maximum observed test value plus 1 . All the other cutoff values are the averages of two consecutive ordered observed test values. ing to the WHO/UNAIDS recommendation, TB-infected patients should be tested for HIV (15).

\subsection{Conclusions}

Hospital admission could be an appropriate momentum for providing voluntary counseling and testing (VCT). Infection with HBV and HCV are risk factors for concomitant HIV infection, and additional tests should be offered, especially to these persons.

\section{Footnotes}

Authors' Contribution: Study concept and design: SG, HJ, and KL. Analysis and interpretation of data: SG, AHH, and MRR. Drafting of the manuscript: SG, AHH, and MRR. Critical revision of the manuscript for important intellectual content: KL and HJ. Statistical analysis: SG.

Conflict of Interests: None.

Ethical Approval: The present study was approved by the Ethics Committee (ethical committee code: 95-01-62-12889) of Shiraz University of Medical Sciences, Shiraz, Iran (code: IR.SUMS.MED.REC. 95-01-62-12889).

Funding/Support: No.

Informed Consent: Written informed consent was obtained.

\section{References}

1. Williamson LM, Dodds JP, Mercey DE, Hart GJ, Johnson AM. Sexual risk behaviour and knowledge of HIV status among community samples of gay men in the UK. AIDS. 2008;22(9):1063-70. doi: 10.1097/QAD.ob013e3282f8af9b. [PubMed: 18520350]. 
2. Su Y, Ding G, Reilly KH, Norris JL, Liu H, Li Z, et al. Loss to follow-up and HIV incidence in female sex workers in Kaiyuan, Yunnan Province China: a nine year longitudinal study. BMC Infect Dis. 2016;16(1):526. doi: 10.1186/s12879-016-1854-y. [PubMed: 27686152]. [PubMed Central: PMC5041379].

3. Ganju D, Ramesh S, Saggurti N. Factors associated with HIV testing among male injecting drug users: findings from a cross-sectional behavioural and biological survey in Manipur and Nagaland, India. Harm Reduct J. 2016;13(1):21. doi: 10.1186/s12954-016-0110-5. [PubMed: 27324253]. [PubMed Central: PMC4915098].

4. Guimaraes RA, Rodovalho AG, Fernandes IL, Silva GC, de Felipe RL, Vera I, et al. Transactional Sex among Noninjecting Illicit Drug Users: Implications for HIV Transmission. ScientificWorldjournal. 2016;2016:4690628. doi: 10.1155/2016/4690628. [PubMed: 27648467]. [PubMed Central: PMC5018331].

5. Macgowan R, Margolis A, Richardson-Moore A, Wang T, Lalota M, French PT, et al. Voluntary rapid human immunodeficiency virus (HIV) testing in jails. Sex Transm Dis. 2009;36(2 Suppl):S9-13. doi: 10.1097/OLQ.0b013e318148b6b1. [PubMed:17724428].

6. Lyons MS, Lindsell CJ, Ledyard HK, Frame PT, Trott AT. Emergency department HIV testing and counseling: an ongoing experience in a low-prevalence area. Ann Emerg Med. 2005;46(1):22-8. doi: 10.1016/j.annemergmed.2004.12.022. [PubMed: 15988422].

7. Haghdoost. Modelling of HIV/AIDS in Iran up to 2014. J AIDS HIV Res. 2011;3(12). doi: 10.5897/jahr11.030.

8. Rahmati-Najarkolaei F, Niknami S, Aminshokravi F, Bazargan M, Ahmadi F, Hadjizadeh E, et al. Experiences of stigma in healthcare settings among adults living with HIV in the Islamic Republic of Iran.J Int AIDS Soc. 2010;13:27. doi: 10.1186/1758-2652-13-27. [PubMed: 20649967]. [PubMed Central: PMC2919446].

9. Rothman RE. Current Centers for Disease Control and Prevention guidelines for HIV counseling, testing, and referral: critical role of and a call to action for emergency physicians. Ann Emerg Med. 2004;44(1):31-42. doi: 10.1016/j.annemergmed.2004.01.016. [PubMed: 15226706].

10. Kabapy AF, Shatat HZ, Abd El-Wahab EW. Attributes of HIV infection over decades (1982-2018): A systematic review and meta-analysis. Transbound Emerg Dis. 2020;67(6):2372-88. doi: 10.1111/tbed.13621. [PubMed: 32396689].

11. van den Bogaart L, Ranzani A, Oreni L, Giacomelli A, Corbellino M, Rusconi S, et al. Overlooked cases of HIV infection: An Italian tale of missed diagnostic opportunities. Eur J Intern Med. 2020;73:30-5. doi: 10.1016/j.ejim.2019.09.006. [PubMed: 31635999].

12. Wanyenze RK, Nawavvu C, Namale AS, Mayanja B, Bunnell R, Abang $B$, et al. Acceptability of routine HIV counselling and testing, and HIV seroprevalence in Ugandan hospitals. Bull World Health Organ. 2008;86(4):302-9. doi: 10.2471/blt.07.042580. [PubMed: 18438519]. [PubMed Central: PMC2647415].

13. Hsieh YH, Rothman RE, Newman-Toker DE, Kelen GD. National estimation of rates of HIV serology testing in US emergency departments 1993-2005: baseline prior to the 2006 Centers for Disease Control and Prevention recommendations. AIDS. 2008;22(16):2127-34. doi: 10.1097/QAD.0b013e328310e066. [PubMed: 18832876].

14. Desai S, Tavoschi L, Sullivan AK, Combs L, Raben D, Delpech V, et al. HIV testing strategies employed in health care settings in the European Union/European Economic Area (EU/EEA): evidence from a systematic review. HIV Med.2020;21(3):163-79. doi: 10.1111/hiv.12809. [PubMed: 31729150]. [PubMed Central: PMC7065119].

15. UNAIDS W. Guidance on provider-initiated HIV testing and counselling in health facilities. Geneva, Switzerland: World Health Organisation, UNAIDS; 2007.

16. Iran's Ministry of Health and Medical Education. A comprehensive package of care and treatment guidelines for HIV cases. Tehran: Centre for Disease and prevention; 2020.

17. Karamouzian M, Akbari M, Haghdoost AA, Setayesh H, Zolala F. "I am dead to them": HIV-related stigma experienced by people living with HIV in Kerman, Iran. J Assoc Nurses AIDS Care. 2015;26(1):46-56. doi: 10.1016/j.jana.2014.04.005. [PubMed: 24856436].

18. SeyedAlinaghi S, Paydary K, Afsar Kazerooni P, Hosseini M, Sedaghat A, Emamzadeh-Fard S, et al. Evaluation of Stigma Index Among People Living With HIV/AIDS (PLWHA) in Six Cities in Iran. Thrita J Med Sci. 2013;2(2):69-75. doi: 10.5812/thrita.11801.

19. Saki M, Mohammad Khan Kermanshahi S, Mohammadi E, Mohraz M. Perception of Patients With HIV/AIDS From Stigma and Discrimination. Iran Red Crescent Med J. 2015;17(6). e23638. doi: 10.5812/ircmj.23638v2. [PubMed: 26290751]. [PubMed Central: PMC4537784].

20. Zarei N, Joulaei H, Darabi E, Fararouei M. Stigmatized Attitude of Healthcare Providers: A Barrier for Delivering Health Services to HIV Positive Patients. Int J Community Based Nurs Midwifery. 2015;3(4):292300. [PubMed: 26448956]. [PubMed Central: PMC4591575].

21. Mirzazadeh A, Nedjat S, Navadeh S, Haghdoost A, Mansournia MA, McFarland W, et al. HIV and related risk behaviors among female sex workers in Iran: bias-adjusted estimates from the $2010 \mathrm{Na}$ tional Bio-Behavoral Survey. AIDS Behav. 2014;18 Suppl 1:S19-24. doi: 10.1007/s10461-013-0548-3. [PubMed: 23857356].

22. Khoshnood K, Hashemian F, Moshtagh N, Eftekahri M, Setayesh S. T03O-08 Social stigma, homosexuality and transsexuality in Iran. Sexologies. 2008;17. doi: 10.1016/s1158-1360(08)72705-1.

23. Ryan S, Hahn E, Rao A, Mwinnyaa G, BlackJ, Maharaj R, et al. The impact of HIV knowledge and attitudes on HIV testing acceptance among patients in an emergency department in the Eastern Cape, South Africa. BMC Public Health. 2020;20(1):1066. doi: 10.1186/s12889-020-09170-x. [PubMed: 32631297]. [PubMed Central: PMC7339484].

24. Goggin MA, Davidson AJ, Cantril SV, O'Keefe LK, Douglas JM. The extent of undiagnosed HIV infection among emergency department patients: results of a blinded seroprevalence survey and a pilot HIV testing program. J Emerg Med. 2000;19(1):13-9. doi: 10.1016/s07364679(00)00175-x. [PubMed: 10863112].

25. Brown J, Shesser R, Simon G, Bahn M, Czarnogorski M, Kuo I, et al. Routine HIV screening in the emergency department using the new US Centers for Disease Control and Prevention Guidelines: results from a high-prevalence area. J Acquir Immune Defic Syndr. 2007;46(4):395401. doi:10.1097/qai.ob013e3181582d82. [PubMed: 18077831].

26. Kassa G, Dougherty G, Madevu-Matson C, Egesimba G, Sartie K, Akinjeji A, et al. Improving inpatient provider-initiated HIV testing and counseling in Sierra Leone. PLoS One. 2020;15(7). e0236358. doi: 10.1371/journal.pone.0236358. [PubMed: 32706810]. [PubMed Central: PMC7380619].

27. HIV/AIDS JUNPo. 90-90-90: an ambitious treatment target to help end the AIDS epidemic. Geneva: Unaids; 2014.

28. Champenois K, Cousien A, Cuzin L, Le Vu S, Deuffic-Burban S, Lanoy E, et al. Missed opportunities for HIV testing in newly-HIVdiagnosed patients, a cross sectional study. BMC Infect Dis. 2013;13:200. doi: 10.1186/1471-2334-13-200. [PubMed: 23638870]. [PubMed Central: PMC3652743].

29. Koziel MJ, Peters MG. Viral Hepatitis in HIV Infection. N Engl J Med. 2007;356(14):1445-54. doi:10.1056/NEJMra065142.

30. Sulkowski MS. Viral hepatitis and HIV coinfection. J Hepatol. 2008;48(2):353-67. doi:10.1016/j.jhep.2007.11.009. [PubMed:18155314].

31. Siza C, Bixler D, Davidson S. Proportion and Characterization of Coinfections of HIV and Hepatitis C or Hepatitis B among People with HIV in Alabama, 2007-2016. South Med J. 2020;113(6):298-304. doi: 10.14423/SMJ.0000000000001104. [PubMed: 32483640].

32. Fallahzadeh $\mathrm{H}$, Morowatisharifabad M, Ehrampoosh MH. HIV/AIDS epidemic features and trends in Iran, 1986-2006. AIDS Behav. 
2009;13(2):297-302. doi: 10.1007/s10461-008-9452-7. [PubMed: 18770025].

33. Lotfi R, Ramezani Tehrani F, Yaghmaei F, Hajizadeh E. Barriers to condom use among women at risk of HIV/AIDS: a qualitative study from Iran. BMC Womens Health. 2012;12:13. doi: 10.1186/1472-6874-12-13. [PubMed: 22624530]. [PubMed Central: PMC3519504].

34. Razani N, Mohraz M, Kheirandish P, Malekinejad M, Malekafzali
$\mathrm{H}$, Mokri A, et al. HIV risk behavior among injection drug users in Tehran, Iran. Addiction. 2007;102(9):1472-82. doi: 10.1111/j.13600443.2007.01914.x. [PubMed: 17645427].

35. Fahimfar N, Sedaghat A, Hatami H, Kamali K, Gooya M. Counseling and Harm Reduction Centers for Vulnerable Women to HIV|AIDS in Iran. Iran J Public Health. 2013;42(Supple1):98-104. [PubMed: 23865025]. [PubMed Central: PMC3712587]. 